\title{
O QUADRO DO CONTRATO COMUNICACIONAL DE PATRICK CHARAUDEAU E O TEXTO LITERÁRIO*
}

\section{Renato de Mello**}

\begin{abstract}
Resumo: Este texto tem o objetivo de refletir sobre o quadro do contrato comunicacional de Patrick Charaudeau e sua aplicação no texto literário. Para Charaudeau (1984), uma teoria do discurso nāo pode privar-se de uma definição de sujeito da linguagem. Na troca linguageira, os sujeitos se constituem como comunicante, enunciador, destinatário e interpretante. O uso da Teoria Semiolingüistica e do quadro comunicacional em textos literários se justifica por se acreditar que eles sejam capazes de dar conta do texto ficcional e por ajudar a esclarecer pontos complexos na estrutura do texto, nas instâncias enunciativas que compõem o texto literário.
\end{abstract}

Para CHARAUDEAU (1984:68-75), uma teoria do discurso não pode privar-se de uma definição dos sujeitos do ato de linguagem. ${ }^{1}$ Entendendo como "discurso" o lugar da encenação da significação, ele nã̃o deve ser confundido com "texto". "Texto" deve ser entendido como um objeto que representa a materialização da encenação do ato de linguagem. Ele é um resultado sempre singular de um processo que depende de um sujeito falante particular e

* Recebido para publicaçāo em março de 2003.

" Professor da Faculdade de Letras/UFMG.

1 O que dissermos sobre a Teoria Semiolingüística de Charaudeau e, principalmente, sobre o quadro do contrato comunicacional, parafraseia o que diz o autor no texto "Une théorie des sujets du langage" (1984). 
de circunstâncias de produção particulares. Segundo o teórico, cada texto se acha atravessado por diversos discursos ligados aos gêneros ou às situações diferentes. "Discurso" não deve, tampouco, ser entendido como unidade que ultrapassa a frase. A relação entre diversas frases não constitui, necessariamente, a unidade "discurso". É necessário que esta seqüência de frases corresponda a uma expectativa linguageira (enjeu) entre vários parceiros em circunstâncias bem determinadas. Ao contrário, uma frase, uma palavra, um gesto, ou até mesmo o silêncio, podem ser portadores de discurso, a partir do momento em que eles respondem a esta condição.

O termo "discurso", segundo Charaudeau, pode, assim, ser utilizado em dois sentidos:

1. em relação ao fenômeno de encenação do ato de linguagem que, por sua vez, compreende dois circuitos:

a) um circuito externo (o situacional) que representa o lugar do Fazer psicossocial;

b) um circuito interno (o comunicacional) que representa o lugar de organização do Dizer.

2. "discurso" pode ser relacionado a um conjunto coerente de saberes partilhados, construídos de maneira inconsciente por indivíduos de um grupo social.

CHARAUDEAU (1984:73) parte da definição dicionarizada de "sujeito" para dizer que ele é "... un lieu de production de la signification langagière auquel revient cette signification pour le constituer." O sujeito não é, desse modo, nem um indivíduo preciso, nem tampouco um ser coletivo específico, mas uma abstração, um lugar de abstração da produção/interpretação da significação, dependendo do lugar que esse sujeito ocupa no ato de linguagem. Ele pode ser um sujeito comunicante, enunciador, destinatário ou um sujeito interpretante.

Vale lembrar que, no contrato de comunicação, os parceiros da troca linguageira estão sujeitos àquilo que CHARAUDEAU 
(1992:633-835) chama de "Modos de Organização do Discurso", ou seja, os princípios de organização da matéria lingüística, princípios que dependem da finalidade comunicativa do sujeito falante: enunciar, descrever, contar, argumentar. Assim, os modos de organização do discurso são: o descritivo, que consiste em saber nomear e qualificar os seres do mundo, com maior ou menor subjetividade; o narrativo, que consiste em saber descrever as ações dos protagonistas de uma história, realçando seus diferentes percursos e buscas; o argumentativo, que consiste num saber organizar as redes de causalidade explicativa dos acontecimentos, estabelecendo as provas do verdadeiro, do falso ou do verossímil; e o enunciativo, que tem por vocação essencial dar conta da posição do locutor em relação a si mesmo e em relação ao interlocutor. $O$ enunciativo é responsável pela intersubjetividade, pela identidade e pela alteridade dos sujeitos da linguagem. Isso faz com que esse modo intervenha nos outros três, que os comande. Esses modos podem se manifestar tanto simultaneamente quanto pontualmente.

Todo esse preâmbulo serve para podermos introduzir o quadro criado por Charaudeau para explicar o funcionamento do ato de linguagem, das estratégias discursivas, enfim, do contrato de fala. Vale repetir que, para Charaudeau, o ato de linguagem é um fenômeno que combina o Dizer (no circuito interno, no nível discursivo) e o Fazer (no circuito externo, no nível situacional). $O$ Fazer é o espaço da instância situacional que se define pelo lugar que ocupam os responsáveis, ou melhor, os parceiros deste ato. $\mathrm{E}$ o Dizer é o espaço da instância discursiva que se define como uma encenação ou mise en scène da qual participam seres de fala, ou protagonistas. Dito de outro modo, a teoria empreendida por Charaudeau busca explicar a estruturação do ato de linguagem através da postulação de um dispositivo que compreende um duplo circuito: 
1) uma instância externa, espaço do Fazer psicossocial dos parceiros envolvidos na comunicação, também chamado de espaço de limitações;

2) uma instância interna, espaço da organização do Dizer, também chamado de espaço de estratégias, onde os protagonistas montam suas estratégias (enjeux) de encenação do ato de linguagem. Vejamos como é o quadro do contrato comunicacional proposto por Charaudeau:

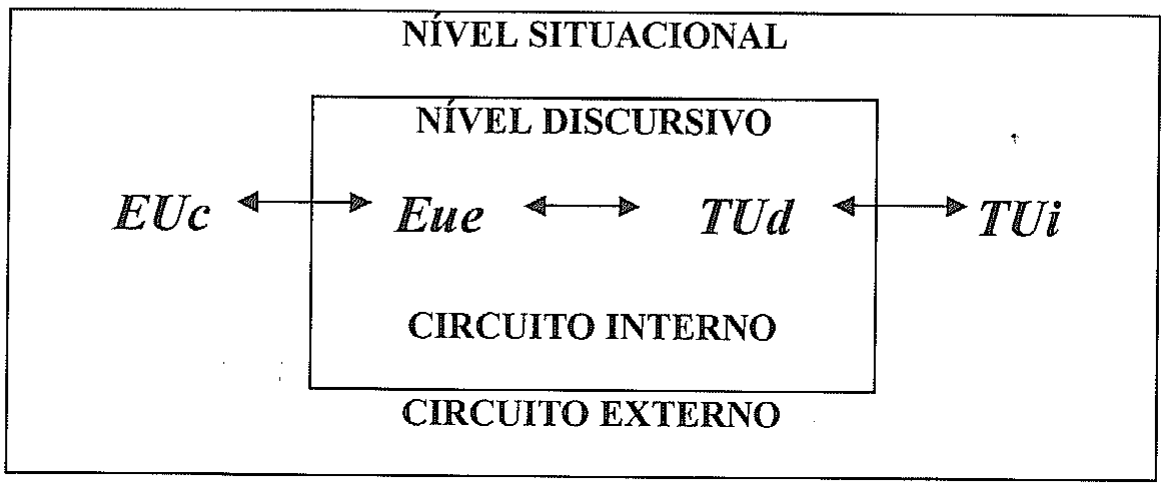

QUADRO 1

Como podemos perceber no Quadro 1, o processo de comunicação é composto de, no mínimo, dois parceiros: o sujeito comunicante (EUc) e o sujeito interpretante (TUi) implicados na experiência de uma relação contratual. O sujeito comunicante (EUc) é o parceiro que tem a iniciativa do processo de produção. Ele procede à encenação do Fazer em função de uma intenção/projeto de palavra ("O que dizer?") e de um como falar ("De que modo dizer?") que se liga às estratégias de manipulação ("Como dizer o que vou dizer de modo a convencer o meu parceiro?"). Para isso, EUc constitui-se em um sujeito enunciador (EUe) que, por sua vez, institui, através do seu projeto de palavra, um sujeito destinatário (TUd) - ambos sujeitos que se definem como seres de fala da enunciação do Dizer: se, por um lado, o EUc e o TUi são os parcei- 
ros da comunicação, por outro, o EUe e.o TUd são os protagonistas da interação linguageira.

EỦc é uma entidade composta: uma instância produtora à qual pertencem todas as outras instâncias, incluindo-se, aqui, o TUi que tem uma relação com EUc muito parecida com aquilo que Benveniste (1988) chama de "relação de transcendência", em que o TUi é um "servidor" do EUc. Assim, tanto EUe quanto TUd e TUi contribuem com EUc para construir uma enunciação, ou melhor, uma co-enunciação, cuja intencionalidade significante corresponde a um projeto comum a eles e do qual podemos dizer que representa a ideologia ou a estética do grupo. O EUe é um ser de fala sempre presente no ato de linguagem, uma imagem de enunciador construída pelo sujeito produtor da fala (EUc): Ele é o veículo por meio do qual EUc "fala". Dito de outro modo, EUe funciona como uma espécie de "porta-voz", ou, segundo a acepção de Charaudeau, como sujeito enunciador da "instância de enunciação discursiva". O TUd é o interlocutor necessário ao EUe que o concebe como "destinatário ideal", no processo interacional. Sendo assim, o TUd estará sempre presente no ato de linguagem explicitamente marcado ou não. TUi, sujeito interpretante, é o parceiro de EUc. Todas essas "pessoas", todas essas "vozes", todos esses "papéis" são concebidos, segundo Charaudeau, como comportamentos linguageiros, como índices semiológicos da encenação do Fazer e do Dizer.

Propomos, a partir da apresentação, ainda que sucinta, da teoria dos sujeitos da linguagem apresentada por Charaudeau, aplicá-la no contexto da literatura. O uso dessa teoria e desse quadro se justifica porque acreditamos que eles sejam capazes de dar conta da especificidade do texto literário, ou pelo menos, de problematizá-lo, que eles sejam capazes de nos ajudar a esclarecer pontos complexos em sua estrutura, principalmente no que diz respeito aos múltiplọs sujeitos. Procederemos, desse modo, ao (re)conhecimento das instâncias enunciativas que compõem o texto 
literário, com a ajuda do quadro comunicacional de Charaudeau.

\section{O Quadro e o Texto Literário}

Tentaremos, aqui, aplicar o quadro de Charaudeau ao texto literário, com o objetivo de esclarecer como funciona o contrato comunicacional entre os múltiplos sujeitos que o compõem. Vejamos como fica o quadro aplicado ao texto literário de um modo geral:

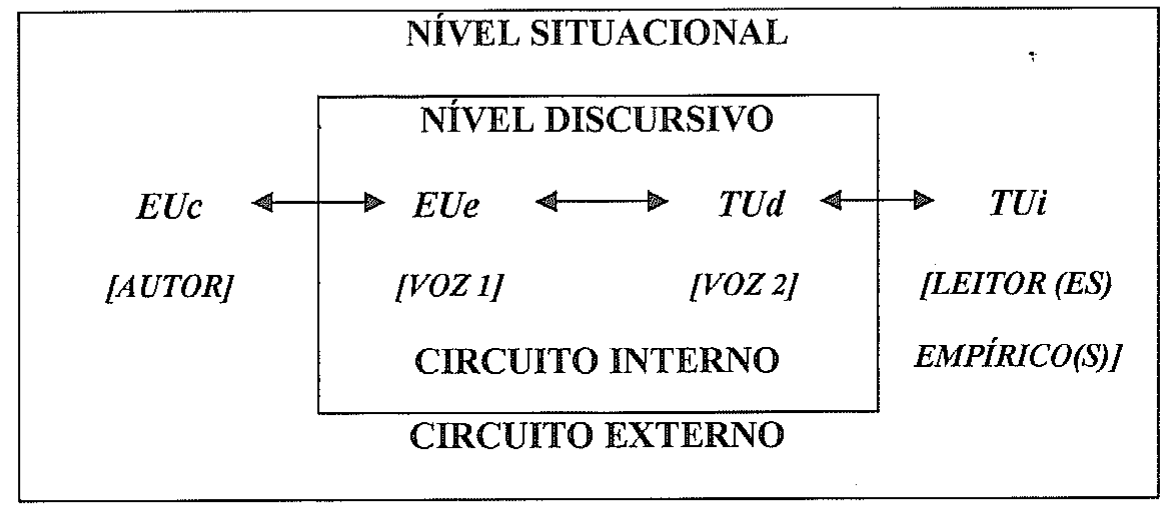

QUADRO 2

Como podemos perceber no Quadro 2, temos as seguintes equivalências: o EUc - sujeito comunicante - é o autor, escritor empírico, aquele que teve a iniciativa do processo de produção, aqui, no caso, de produção literária e teórica. EUc, ao escrever suas obras, o faz, evidentemente, para que elas sejam lidas por alguém. Esse alguém é o leitor, sujeito empírico, aquele que vai efetivamente ler os textos produzidos, ou seja, o TUi. Esse TUi é, desse modo, o parceiro de EUc, aquele que tem a iniciativa do processo de interpretação da obra. Vale repetir que tanto EUc quanto TUi, pertencem a uma mesma esfera situacional, a um universo empírico, ao universo do Fazer, externo ao mundo ficcional. De 
certa forma, podemos dizer que o autor é um locutor que, com seus livros, se dirige a alocutários (os leitores) - os TUis. Ambos são seres psicossociais, podendo ser, ainda que de maneira distinta, identificados, reconhecidos. ${ }^{2}$

Dizemos "de maneira distinta" por uma razão muito simples: o EUc é um só e é mais facilmente (re)conhecido (sexo, idade, categoria sócio-profissional, posição hierárquica, relação parental, pertencimento a uma instituição em domínios públicos e privados, etc.) (CHARAUDEAU, 1984:74)³ Já a identidade categorial, a identificação ou o (re)conhecimento de TUi, é muito mais complexo, visto que TUi são todos os leitores que já leram, que estão lendo ou que poderão vir a ler os textos de EUc. Desse modo, o estatuto e identidade categorial do TUi, ou melhor, dos TUis (sexo, idade, posição social, etc.) tornam-se praticamente impossiveis de serem identificados em sua totalidade ou mesmo em sua particularidade. O TUi só pode ser identificado como "leitor", como "leitor empírico", como aquele que leu ou lê as obras de EUc. Isso nos leva a pensar se realmente EUc e TUi, que estão no mesmo nível situacional, no espaço externo, estão em pé de igualdade quando se trata de sua identificação, de seus estatutos (idade, sexo, categoria sócio-profissional, etc.). Dito de outro modo, TUi-tanto quanto TUd - é, de certa forma, uma expectativa, uma projeção, uma quimera, um lance de dados. Quando dizemos que tanto EUc quanto TUi são parceiros do ato de linguagem em função de sua relação contratual, temos que levar em conta que aquelas entidades que Charaudeau chama de os três componentes mais ou me-

${ }^{2}$ Devemos pensar, ainda, que escrever pressupōe a capacidade de ler e que, assim sendo, o autor é fundamentalmente leitor de si mesmo. Na verdade, ele é o primeiro leitor, visto que ao escrever ele lê necessariamente o que escreve.

${ }^{3}$ Segundo MACHADO (1998:114), o EUc propicia uma situação paradoxal: “... embora o sujeito em questão tenha seu estilo próprio, não deixa também de ser um sujeito-coletivo, já que vive numa determinada sociedade." E a própria autora pergunta: "Como abordar tal sujeito ambivalente numa perspectiva discursiva?" 
nos objetivos tornados pertinentes pela expectativa (enjeu) do ato linguageiro - comunicacional, psicossocial e intencional - são realmente mais ou menos objetivas:

1. O comunicacional é concebido, segundo Charaudeau, como o quadro psíquico da situação interacional: os parceiros não estão presentes fisicamente durante o ato linguageiro; enquanto só há um EUc, há um número não conhecido de TUi. Sabemos, entretanto, que são múltiplos. Ambos utilizam-se do canal gráfico (os textos) para se comunicarem. Há, entretanto, uma disparidade no uso desse canal: EUc pode se dirigir a TUi através de seus textos, mas TUi não tem o mesmo acesso, o mesmo canal. Mas, por outro lado, podemos dizer que TUi interage, sim, com EUc, só que através da leitura, da interpretação.

2. O psicossocial é concebido em termos dos estatutos nos quais os parceiros se reconhecem: TUi sabe quase tudo sobre EUc (sexo, idade, categoria sócioprofissional, posição hierárquica, relação de parentesco, pertencimento a uma instituição do domínio público ou privado, etc.) ou pelo menos sabe mais que EUc sabe sobre ele. Entretanto, EUc não sabe nada, ou quase nada sobre TUi, ou melhor, os TUis. Constatamos, assim, que há uma desproporção no (re)conhecimento entre esses dois parceiros. Enfim, podemos dizer que os processos de identificação do leitor são partilhados com os propósitos da obra. O leitor efetivamente se reconhece na autora, ocorrendo a comunicação pela via da identidade mútua leitor-escritora. Além disso, EUc, quando concebe sua obra, no escopo de sua estética particular, projeta uma concepção de leitor, seu suposto TUi. Tal projeção se materializa na obra através da instância da personagem-leitor, um efeito de TUi que EUc cria para seu discurso literário.

3. O intencional é concebido como conhecimento a priori que cada um dos parceiros possui (ou constrói para si) sobre o outro de forma imaginária, fazendo apelo aos saberes supostamente partilhados (intertextualidade, interdiscursividade, etc.). Este com- 
ponente repousa sobre duas questões que constituem os princípios de base de sua realização: sobre o que falam ou qual pode ser a intenção da informação? E como falam ou qual pode ser a intenção estratégica de manipulação? No caso de EUc - autor -, e TUi leitores -, ambos "falam" sobre literatura, sobre ficção ou, em última instância, sobre linguagem. A intenção mais evidente de EUc é ser lido por seus TUis. É claro que é possível ter mais de uma intenção quando se escreve um livro. Ainda que seja somente para passar o tempo, essa também é uma intenção. Por outro lado, a intenção de TUi, ao abrir um livro de EUc, é, a princípio, lê-lo. Mais adiante, veremos quais são as estratégias de manipulação usadas por EUc e como elas as constrói no nível discursivo, no espaço interno, inclusive para simular justamente esses três componentes "mais ou menos objetivos" citados por Charaudeau.

Continuando a análise do quadro 2 , vemos que EUc, ao dirigir-se a 'TUi, não o faz diretamente, ou seja, não dialoga diretamente com seu leitor, no sentido físico da expressão. EUc se vale de suas obras, de sua escrita para "conversar" com seus parceiros. Assim, essa parceria entre EUc e TUi se dá de forma particular. Ela é intermediada pelo texto e, dentro dele, por outras instâncias, por outras "pessoas". Nessa interação linguageira, temos parceiros que estão, segundo Charaudeau (1991:9-12), implicados em uma expectativa (enjeu) de uma relação contratual. Dito de outro modo, ambos precisam, para se relacionarem, se engajar no contrato comunicacional que é regido pelo "postulado de intencionalidade" que, por sua vez, se constitui através de quatro princípios que apresentamos a seguir:

1. O princípio de interação: que define o ato de linguagem como um fenômeno de troca entre parceiros que se encontram em uma relação interativa, não-simétrica, pelo fato de estarem engajados, cada um por sua vez, em dois tipos de comportamentos cognitivos, que dão lugar a um duplo processo de intercompreensão: por um lado, verifica-se um processo de emis- 
são-produção do discurso, por outro lado, um processo de recepção-interpretação do discurso. Correlativamente, eles estão ligados pelo reconhecimento recíproco desses dois papéis de base, que somente podem existir a partir do momento em que o outro, o interlocutor, se engaja no processo de interpretação. Com efeito, não é suficiente que ele represente o papel de um simples receptáculo mecânico, como nas teorias "behavioristas" da comunicação. É mostrando que, para além da recepção, ele está engajado em um processo de interpretação, que esse outro se fará existir como parceiro-interlocutor (ou leitor) e, ao mesmo tempo, fará o emissor existir como parceiro-locutor (ou scripteur).

2. O princípio de Pertinência: que implica que haja da parte dos parceiros desse ato um reconhecimento recíproco de atividades-competências para sermos "oportunos" e termos "direito à palavra". (CHARAUDEAU, 1991:10)

3. O princípio de Influência: que postula que a motivação da intencionalidade do sujeito falante se inscreva numa finalidade acional que leva os parceiros da comunicação a satisfazer o princípio do controle das expectativas.

4. O Princípio de Regulação: que constitui, ao mesmo tempo, a condição para que os parceiros se engajem nos processos de reconhecimento do contrato de comunicação e a condição para se perseguir e se realizar a troca comunicativa.

Esses princípios, ou melhor, essas condições que asseguram o "Postulado de Intencionalidade", que garantem o direito à fala nos levam a três tipos de reconhecimento:

1. O reconhecimento do Saber: um domínio em termos de discurso sobre o mundo;

2. O reconhecimento do Poder: que mede o "grau de adequação" que se estabelece entre a identidade psicossocial do sujeito e seu comportamento enquanto ser linguageiro;

3. O reconhecimento do Saber fazer: que permite julgar o sujeito competente em sua ação de sujeito que comunica. 
Tudo isso mostra que entre EUc e seus TUis existe um contrato comunicacional que permite legitimar o ato de linguagem e identificar os papéis de cada um nessa interação. Possibilita, ainda, a intercompreensão, o reconhecimento recíproco - escritora e leitores empíricos -, a autolegitimação desses papéis, suas intençōes no momento da troca linguageira, além do (re)conhecimento e do controle dessas intençōes.

Como já dissemos, esse contrato comunicacional, quando aplicado ao texto literário, não pode ser assimilado ao contrato comunicacional ordinário. O leitor não tem contato direto com EUc. Não somente por razões materiais, mas, sobretudo, porque faz parte da literatura não colocar em relação direta o autor com seus leitores. Esse contato é possível somente através da instituição literária e de seus rituais. Desse modo, a comunicação literária anula qualquer possibilidade de resposta por parte de seu público. Dito de outro modo, a comunicação literária é uma pseudocomunicação e a enunciação é uma pseudo-enunciação. (MAINGUENEAU, 1990:9)

Abandonando, por um momento, o universo situacional, o nível externo do processo de comunicação, o nível do Fazer, passamos ao nível interno, ao universo discursivo, o nível do Dizer, na relação contratual, no qual são instituídos os outros dois parceiros $^{4}$ - EUe e TUd - ambos criados por EUc para se comunicar com TUi.

EUc, ao escrever, instaura uma instância que é, de certa forma, um desdobramento de si própria: o EUe. EUc enuncia através de uma outra voz que não é a sua, mas é, ao mesmo tempo, sua. EUe é, na verdade, um ser de palavra, um protagonista do Dizer

${ }^{4}$ Charaudeau distingue "parceiros" de "protagonistas". Os primeiros são reservados para EUc e TUi, implicados na expectativa (enjeu) de uma relação contratual; os segundos designam EUe e TUd, sujeitos de fala da encenação do Dizer produzida pelos dois primeiros. 
de EUc. Isso equivale a dizer que EUe é algo ou alguém construído por EUc. Existe pois uma divisória (que liga e separa ao mesmo tempo) entre a instância produtora - o EUc, e o responsável pela enunciação - o EUe. Conforme anunciamos no Quadro 2, o EUe, na obra, é, em quase sua totalidade, uma voz anônima que "dirige" a narrativa.

EUe, (voz 1), se dirige, se divide ou se desdobra, por sua vez, em TUd que, por sua vez, também é uma voz (voz 2). Por hora, vale dizer que tanto EUe quanto TUd são personagens. Entendemos, aqui, que as personagens da obra são locutores quando suas vozes se deixam ouvir por meio do discurso direto. Nesse caso, podemos dizer que as personagens são responsáveis por suas enunciações. Nesse universo discursivo temos, assim, um EUe locutor que se dirige a um TUd, sujeito destinatário que, por sua vez, também é um sujeito de palavras, que interpreta o que EUe the diz. Isso se dá de forma interativa, o que vale dizer que o ato de linguagem é dinâmico, que tanto EUe se torna TUd, quanto TUd se torna EUe em um diálogo, em uma troca linguageira. O locutor se torna, assim, alocutário e vice-versa. O locutor, tanto quanto o alocutário, é um ser do discurso, um sujeito construído pelo texto a serviço de seus fins. Eles não podem e não devem ser confundidos com sujeitos empíricos, com EUc e TUi, que estão no nível externo do quadro, na instância situacional, do Fazer. EUe e TUd constituem a mise en scène. Entretanto, não podemos nos esquecer de que EUc e TUi também podem ser chamados de locutor e alocutário. $\mathrm{O}$ autor é o locutor e seus leitores são os alocutários no processo comunicacional, só que em um outro nível, no nível situacional. Também não podemos nos esquecer de que na obra o narrador - EUe - é, quase sempre, um narrador-personagem, alguém que está no mesmo nível discursivo de TUd, uma personagem.

Nessa mise en scène, no nível discursivo, EUc pode introduzir, entretanto, um TUd leitor, um representante, ou melhor, um 
desdobramento do TUi. O autor-, através de seu representante, ou melhor, de seu desdobramento - o EUe - pode criar um TUd que, ao interagir com EUe, torna-se, no processo interativo, um EUe leitor. Temos, assim, a representação do leitor nas instâncias do EUe, do TUd e, evidentemente, do TUi. Podemos também dizer que, já que todos os três são, de certa forma, criação, desdobramento do EUc, o leitor, na verdade está presente nas quatro instâncias, ou nas quatro "pessoas". O leitor, que é implícito, imaginado, é, também, enunciador, interpretante, locutor, alocutário, alvo, argumentante, destinatário, modelo, invocado, genérico, atestado, empírico, instituído, idealizado, virtual, cúmplice, enfim, ele é dialógico, polifônico, múltiplo e polissêmico.

Percebemos, dessa forma, que EUc, EUe, TUd, TUi, escritor, narrador-personagem, personagem e leitor, tornam a abordagem do texto literário algo inovador na (re)constituição dos múltiplos sujeitos. Os papéis, ou melhor, as funções e os estatutos das personagens passam a ser vistos sob outra ótica e o leitor se vê obrigado a (re)definir tudo e todos, inclusive a si próprio.

Torna-se fácil, assim, reconhecer a riqueza, a complexidade, a rentabilidade de um quadro como o do contrato comunicacional de Charaudeau, aplicável, até que provem o contrário, a todas as formas de comunicação, incluindo-se, evidentemente, o texto literário.

Résumé: Ce texte propose une réflexion sur le tableau du contrat communicationnel de Patrick Charaudeau et son aplication au texte littéraire. Pour CHARAUDEAU (1984), une théorie du discours ne peut pas se passer d'une définition de sujet du langage. Dans l'échange langagier, le sujet peut se construire en tant que communiquant, énonciateur, destinataire et interprétant. L'utilisation de la Théorie Semiolinguistique et du tableau du contrat communicationel en textes littéraires se justifie parce qu'on croit qu'ils peuvent nous aider à mieux connaître 
le texte fictionel et a éclaircir des points complexes dans la structure du texte, dans les instances d'énonciation qui composent le texte littéraire.

\section{Referências Bibliográficas}

CHARAUDEAU, P. Grammaire du sens et de l'expression. Paris: Hachette, 1992.

CHARAUDEAU, P. Rôles sociaux et rôles langagiers. In: Actes du Coloque sur l'interaction. Aix-en-Provence, set. 1991.

CHARAUDEAU, P. Une théorie du sujet du langage. In: Langage et société. no 28. Paris: Maison des Sciences de L'Homme, jun. 1984.

MACHADO, I. L. Análise do discurso e seus múltiplos sujeitos. In: MACHADO, I. L. (Org.) Teorias e Práticas Discursivas. Estudos em Análise do Discurso. Belo Horizonte: Carol Borges/NAD-FALE-UFMG. 1998. p.111-121.

MAINGUENEAU, D. Pragmatique pour le discours littéraire. Paris: Bordas, 1990.

MELLO, R. Análise discursiva dos múltiplos sujeitos e silêncios sarrautianos. Tese de Doutorado. FALE. UFMG, 2002. 